\title{
AN EXPERIMENTAL ANALYSIS OF OPTIMAL RENEWABLE RESOURCE MANAGEMENT: THE FISHERY*
}

by

John D Hey*, Tibor Neugebauer* and Abdolkarim Sadrieh**

*Dept. Economics and Related Studies, University of York, Yo10 5dd York, UK

**Dept. of Economics, Tilburg University, PO Box 90153, 5000 LE Tilburg, The Netherlands and Laboratory for Experimental

Economics, University of Bonn, Konrad-Adenauer-Allee 24-42, 53115 Bonn, Germany

\section{Comments welcome}

$3 / 28 / 2002$

\begin{abstract}
This paper investigates experimentally the extraction-decisions of a sole-owner of a fishery, the population dynamics of which behave according to the standard deterministic logistic growth model. Four treatments were implemented which differed in the level of information supplied to the experimental subjects. The theoretical solution was used to evaluate the behaviour of the subjects in the experiment. The experimental data reveal high efficiency losses due to the lack of information about population dynamics, with efficiency varying across treatments and with the amount of information.
\end{abstract}

JEL classifications: C91, D81, Q22

Keywords: Experimental economics, renewable resources, dynamic decision making, decisions under risk and uncertainty, misperceptions of feedback

\footnotetext{
\$ This paper is part of the EU-TMR Research Network ENDEAR (FMRX-CT98-0238). The authors are grateful to seminar participants at Magdeburg, York and at the ESA 2001 conference Barcelona for valuable comments.
} 


\section{Introduction}

Renewable resources are those for which the stock can be continually replenished. Fishery resources are renewable. However, if (through human activities or otherwise) the population of some species is drawn down beyond a critical threshold, the species can become extinct. A recent concern has been with the dramatic decline in the populations of several valuable fish species such as cod, halibut and haddock. Since the seminal article of Gordon (1954), difficulties in effective management of fisheries have been attributed to the resource's peculiarity of being a common property. However, due to the new law of the sea (established in 1982) more than 90 percent of fish resources are now under the exclusive jurisdiction of coastal states and can, thus, be protected. Every year the total allowable catch (henceforth TAC) is determined. The TAC is allocated among the fishermen, the individual quotas are transferable and can be reallocated through a market for certificates. In theory an optimal resource management results. In practice, however, errors might occur when the decisionmaker determines the TAC, because the size, growth and population dynamics of the fishery are not exactly known. As one consequence, the estimated stock size of the species is likely to be different from the actual one.

The importance of the accuracy of stock surveys, and of the knowledge of the growth function, for the purpose of establishing the TAC is considered in this paper. We set up a laboratory study to measure the efficiency of the extraction-decisions in a deterministic environment under different informational conditions. We find that if the growth function is known, subjects' extraction-decisions are nearly twice as efficient as when the growth function is not known. Furthermore, accuracy of the stock estimate enhances the decision-makers' efficiency only if the growth function of the species is known.

The paper is organised as follows. Departing from the classical logistical growth model, we derive the finite-horizon extraction plan in the subsequent (second) section. In the third section we present the design of the four experimental conditions in which experimental subjects were confronted with different levels of information. In the fourth section the results of our study are presented and related to the received literature. Finally, the fifth section concludes.

\section{Theoretical Considerations}

Consider the standard logistic growth function of stock $x_{t}$ (as depicted in Figure 1), $F\left(x_{t}\right)=r x_{t}\left(1-x_{t} / K\right)$, where $r>0$ denotes the species' intrinsic growth factor and $K>0$ denotes the 
carrying capacity ${ }^{1}$. In the open-access fishery, the equilibrium level of the resource stock is determined by the ratio of harvesting cost to the price of the resource. Given costless harvesting in a commercial fishery (as in the experiment), the species will be extinct for any positive price. If the intrinsic growth-factor $r$ is smaller than the interest rate $\delta$ and costs are equal to zero, extinction may be the only solution even in the optimal harvesting policy.

Figure 1. Logistic growth function for $K=1000$ and $r=1.5$

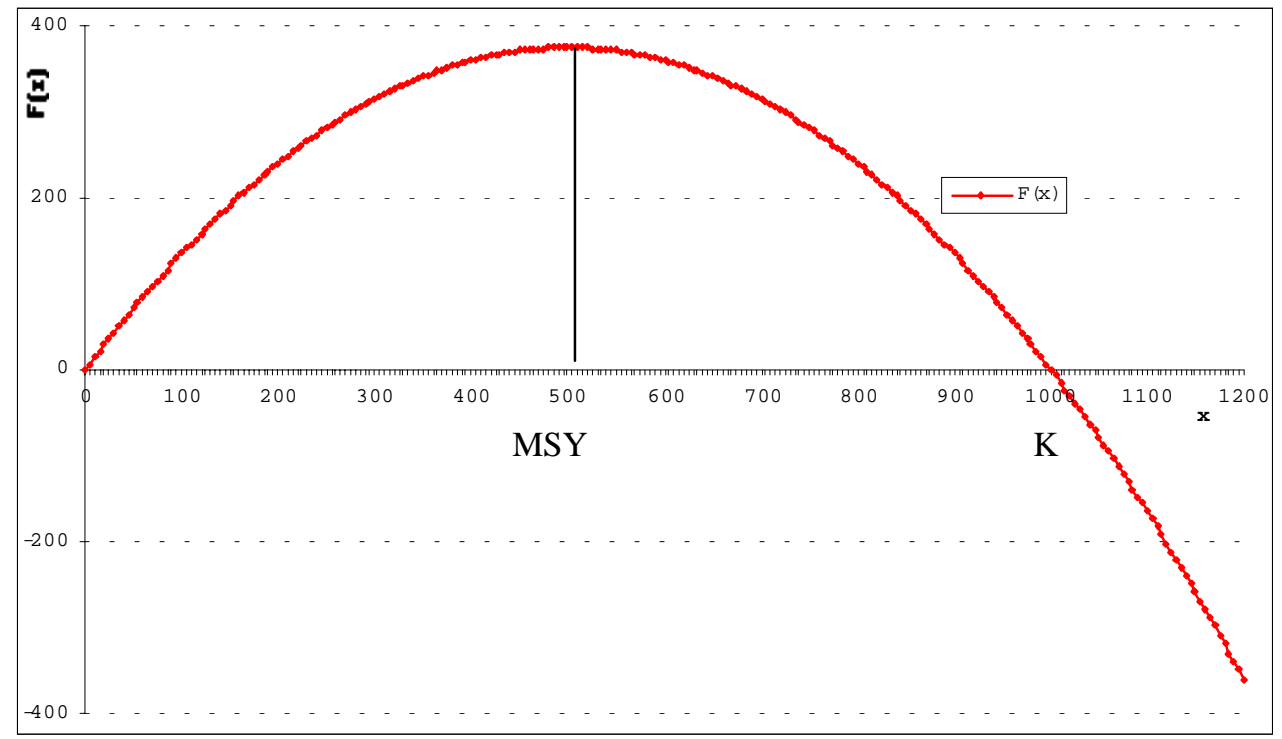

Note: MSY denotes the maximal sustainable yield. The graph corresponds to the experimental parameterisation.

Let the discount factor be denoted by $\rho=1 /(1+\delta)$, let the price be normalised to one and for simplicity assume harvesting costs to be equal to zero, the optimal extraction policy in the finite-horizon management problem can be determined as the solution to the following programme.

$$
\begin{array}{ll}
\max & V=\sum_{\mathrm{t}=0}^{\mathrm{T}} \rho^{t} y_{t} \\
\text { s.t. } & x_{t+1}=z_{t}+F\left(z_{t}\right) \\
& z_{t}=x_{t}-y_{t} \\
& x_{0}=K
\end{array}
$$

Here, $x_{t}$ denotes the stock before extraction, $z_{t}$ denotes the stock size after extraction and $y_{t}$ (the control variable) denotes the extraction in period $t$. The optimal solution to this problem can be calculated by means of Bellman (1957)'s principle of optimality. Define $J_{n}(x)$ as the

\footnotetext{
${ }^{1}$ This is the maximum viable (long-run) stock size.
} 
maximum total value when only $n$ periods remain, and the state variable at the outset of these $n$ periods is $x$. Thus, beginning with the last period, the decision-maker faces the following problem.

$$
J_{0}(x)=\max _{y_{T}}\left\{\rho^{T} y_{T}\right\}
$$

The final extraction $y_{T}$ that maximises this value function is equal to the maximal feasible $y_{T}$, which coincides with the stock remaining at time $T, x_{T}$. Hence, $J_{0}(x)=\rho^{T} x_{T}$. Given $J_{0}(x)$, we can calculate the next term of the maximisation procedure, $J_{l}(x)$.

$$
J_{1}(x)=\max _{y_{T-1}}\left\{\rho^{T-1} y_{T-1}+J_{0}\right\}
$$

As a result, the basic equation $F^{\prime}\left(z_{T-1}\right)=\delta$ follows from the first order conditions, where $F^{\prime}\left(z_{T-}\right.$ $\left.{ }_{1}\right)=r\left(1-2 z_{T-1} / K\right)$. Therefore, $z_{T-1}=K / 2(1-\delta / r)$, and $y_{T-1}=x_{T-1}-z_{T-1} . J_{1}(x)$ equals, thus, $J_{1}(x)=\rho^{T-1}\left(x_{T \text { - }}\right.$ $\left.{ }_{1}-z_{T-1}\right)+\rho^{T}\left(F\left(z_{T-1}\right)+z_{T-1}\right)$. Proceeding by backward induction, the following general expression can be found

$$
\begin{aligned}
J_{n}(x) & =\max _{y_{T-n}}\left(\rho^{T-n} y_{T-n}+J_{n-1}(x)\right) \\
& =\rho^{T-n}\left(x_{T-n}-z\right)+\sum_{j=0}^{n-1} F(z) \rho^{T-j}+\rho^{T} z \\
y_{t}= & x_{t}-z^{*} \\
z_{t}= & z^{*}=\frac{K}{2}\left(1-\frac{\delta}{r}\right)
\end{aligned}
$$

which implies for the first term $J_{T}=x_{0^{-}} z^{*}+\sum F(z) \rho^{T-j}+\rho^{T} z^{*}$, and $y_{0}=x_{0^{-}} z^{*}=K-z^{*}$. Since the afterextraction stock size $z^{*}$ is constant for all $t<T$ and growth is deterministic it follows that the before-extraction stock size $x_{t}$ is constant for $t>1$ and, consequently, the extraction $y_{t}$ is constant for all $1<t<T$. This result holds for any time horizon $T<\infty$, and also in the infinite horizon management problem ${ }^{2}$. The extraction plan in the finite-horizon management problem coincides with the one in the infinite-horizon case (exclusive of the last period when the resource has to be extinguished) because (in absence of harvesting costs) the marginal productivity of the resource after extraction $F^{\prime}\left(z^{*}\right)$ must always be equal to the interest rate $\delta$.

Since both problems yield the same solution and the infinite-horizon problem is impossible to implement in the laboratory, it is necessary to tackle the fishery management problem in the laboratory in a finite-horizon setting ${ }^{3}$.

\footnotetext{
${ }^{2}$ See Clark (1976, Ch. 2) for a derivation of a solution to the infinite-horizon problem and a discussion.

${ }^{3}$ Given the earth does not exist indefinitely this approach does not seem less plausible, either.
} 


\section{The Experimental Design}

In the experiment, a subject had to decide hundred times on the TAC, i.e., how much to extract from a privately owned resource stock. The extracted units were saved on the subject's account and the growth function was applied to the units that remained in the resource stock after an extraction. The discount rate was $\delta=0$. The applied growth function was logistic with a carrying capacity of $K=1000$ units and the intrinsic growth parameter was $r=1.5$. The initial stock size coincided with the carrying capacity, $x_{0}=K=1000$.

Table 1. Experimental treatments

\begin{tabular}{l|c}
\hline Informational condition & Treatment \\
\hline Information about exact stock size and growth & $\mathrm{T} 1$ \\
Information about growth and noisy signal about stock size & $\mathrm{T} 2$ \\
Information about exact stock size & $\mathrm{T} 3$ \\
Noisy signal about stock size & $\mathrm{T} 4$ \\
\hline
\end{tabular}

Four treatments were considered in the experiment which differed in the level of on-screen information; in Table 1 an overview is given. Before every extraction the subject was posted a signal revealing information about the resource's stock size. This signal was accurate in the treatments $T 1$ and $T 3$, i.e., equal to the resource stock $x_{t}$, and in the other 2 treatments noisy, i.e., the signal was equal to the resource stock multiplied by a uniform random draw from the interval $[0.75,1.25]$. In the treatments $T 1$ and $T 2$, an on-screen facility (in Table 1 referred to as information about growth) was provided by means of which a subject could anticipate the consequences of any possible extraction for the nearest future before she/he confirmed an extraction ${ }^{4}$. Subjects were instructed accordingly ${ }^{5}$.

\footnotetext{
${ }^{4}$ Before a harvest-decision, the subject would see a table with 11 possible extractions in 10 percentiles of the signalled stock in the first column. In the second column the corresponding after-extraction stock sizes were displayed, in the third column the resulting next stock sizes, in the fourth column the growth of the resource (i.e., the difference between the third and the second column) was displayed, and finally the savings were recorded in the fifth column. Additionally, the subject received such information in a scroll-box for any possible extraction she/he would insert. Finally, if the subject was sure about extracting a certain number of units from the resource stock, she/he had to confirm the selection by pressing a button.

${ }^{5}$ Instructions and computer-screen designs are provided in the Appendix.
} 
The experiment was computerised ${ }^{6}$ and of no-label, i.e., subjects were asked to maximise the savings on their accounts. The research interest in the experimental setting was whether efficiency would increase significantly if the amount of information was increased. The individual payoff at the end of the experiment was determined relatively to the subject's efficiency performance: the units that the subject held on the account at the end of the experiment were divided by the maximal possible savings (i.e., 38125, though unknown to the subject $)^{7}$. The attained individual efficiency-ratio was multiplied by the maximal payoff which differed from treatment to treatment ${ }^{8}$. If a subject extinguished the resource before having entered 100 extraction-decisions the experiment would end instantaneously, regardless of the number of decisions entered so far. In order to limit erroneous extractions from the stock, the subject would be forewarned if the extracted number of units exceeded the signalled units; at the other extreme, an extraction-decision of no unit was forewarned, also. In addition, before the $100^{\text {th }}$ decision was going to be taken, the subject was informed that there was no further extraction afterwards. The preceding extractions and on-screen information, including the stock signal before and after extraction as well as the resulting savings, were provided in a history-window which the subject could access at any time of the experiment.

The experimental results which are reported below refer to 48 independent observations. Twelve students taking a laurea in the Faculty of Economics of the University of Bari participated in each of the four treatments. The experiments were conducted in June 2001 in the ESSE laboratory at the University of Bari in Italy.

\section{Experimental Results}

This section reports on the results of our experimental study. It is organised according to the chronological order of extractions: We start by surveying the first extraction-decisions, then we consider the evolution of extraction decisions and consider thereafter subjects' last extractions. As a benchmark we refer to the decisions on the optimal path which would involve an after extraction stock equal to the maximum sustainable yield (i.e., 500 units) and the

\footnotetext{
${ }^{6}$ The software was programmed by means of Abbink and Sadrieh (1995)'s RatImage.

${ }^{7}$ The maximal savings are easily calculated by applying the results from Section 2: first, extracting 500 units to reach the steady state (the maximal sustainable yield since the interest rate is zero); afterwards, extracting 375 units (equal to the growth in the steady state); and finally, in the last decision exterminating the resource.

${ }^{8}$ The maximal payoff in T1 was 25000 ITL, in T2 and T3 30000 ITL, and in T4 35000 ITL (2000 ITL $\approx 1 € \approx$ $1 \$)$. The average payoff was $16.000 \mathrm{ITL}$; the experiment took about an hour.
} 
extinction of the resource with the final extraction. We conclude the section by drawing attention to individual behavioural pattern.

\section{The First Extraction Decisions}

The first extraction decisions induced significant under-harvesting in all treatments (twotailed Wilcoxon signed ranks test at $\alpha=.05, \mathrm{n}=12$ ): subjects extracted less than the optimal 500 units. The deviations from the optimal extraction increased from treatment $\mathrm{T} 1$ through $\mathrm{T} 4$ and differences were significant for all pair-wise comparisons but the T3-T4 pair (one-tailed MannWhitney test at $\left.\alpha=.05, \mathrm{n}_{1}=\mathrm{n}_{2}=12\right)^{9}$. In the treatments T2 and T4 in which the stock signal varied at random between .75 and 1.25 of the actual stock size subjects' extraction-rates increased significantly with the signal only in treatment T2 but not in T4 (one-tailed Spearman rank correlation test at $\alpha=.05, \mathrm{n}=12$ ). These observations indicate that subjects were cautious about not causing irreversible damage to the stock with their first extraction, and particularly were aware of it when their information was limited to a stock signal as in T3-T4. It seems noteworthy that extractions in T3 were lower than in T2 and at the same time they were not significantly greater than in T4 (although signals were accurate in T3 and not in T2 and T4). However, with their information of the stock dynamics, subjects in T2 were enabled to build up an accurate mental picture of the task and could grasp better what effect their decisions would have. Subjects in T3 and T4, in contrast, were ignorant of the stock dynamics and acted more cautiously, because the task appeared to them more complex.

\section{The Evolution Of Extraction-Decisions}

Figure 2 depicts the evolution of average stock levels after extraction in treatments T1-T4. Obviously, over-harvesting was not a major problem in the experiment ${ }^{10}$. This is confirmed by a two-tailed Wilcoxon signed ranks test of the null-hypothesis that subjects over-harvest as likely as they under-harvest. The test is constructed on the number of observations in which a subject's stock size after extraction was below respectively above the optimal one. The pvalues that result from the test are recorded in the first row of Table 2. The test rejects the null-hypothesis only with regard to T3 and T4 in favour of significant under-harvesting at the

\footnotetext{
${ }^{9}$ Average deviations from the optimal first extraction of 500 units were in T1: 122 units (.24), in T2: 154 units (.31), in T3: 343 units (.69) and, finally, in T4: 385 units (.77).

${ }^{10}$ One subject extinguished the resource after 19 extractions in T2. The number of units she extracted then was smaller than the number of units indicated by the noisy signal she received.
} 
Figure 2. Evolution of average stock sizes after extraction in treatments T1-T4 compared to the optimal path

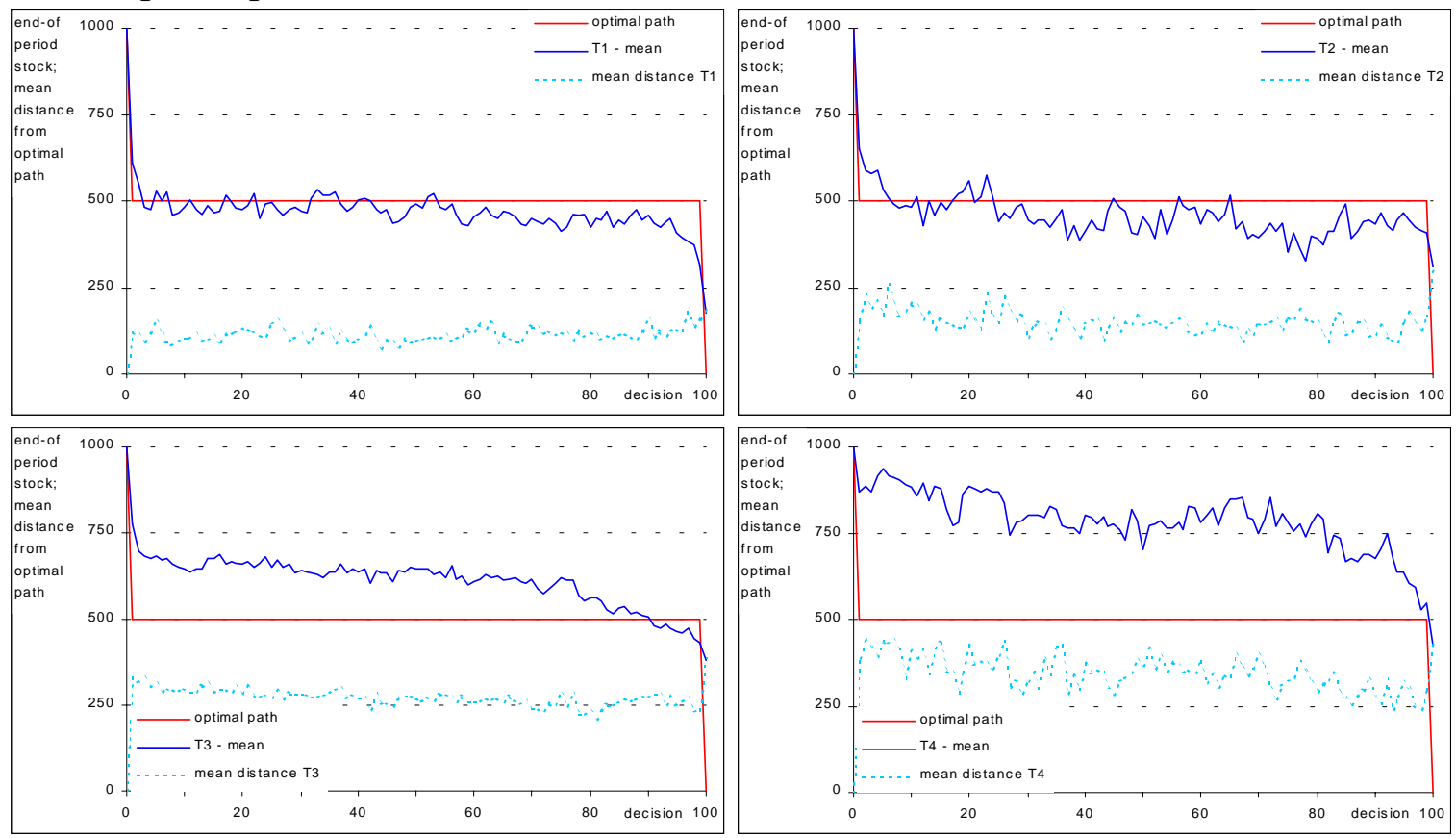

$\alpha=.05$-level of significance. This result reveals important differences to the results of Moxnes (1998a, 1998b) and shows also the limitations of the external validity of our results since empirical data indicate rather over-harvesting. This point is further discussed in the conclusions. However, the propensity to harvest more in T1-T2 than in T3-T4 suggests that subjects are more confident with their extraction decisions when they receive information of the stock dynamics.

From Figure 2 may be noticed that there is a time trend of average distances from the optimal path. Distances increased with time in T1 (Spearman rank correlation test, $\mathrm{p}=.028$, $1<\mathrm{t}<100$ ), and decreased in T2-T4 (Spearman rank correlation test, $\mathrm{p}=.000,1<\mathrm{t}<100$ ). It seems quite intuitive that subjects in treatments T2-T4 improved their performance on average from one decision to the next. Since they learned the environment by means of feedback their cognitive map of the task got increasingly more accurate over the length of the experiment. Given that subjects in $\mathrm{T} 1$ did not receive any information from feedback that they did not know beforehand, it is not 
Table 2. Deviations from the optimal path

\begin{tabular}{|c|c|c|c|c|c|}
\hline & & $\overline{\mathrm{T} 1}$ & $\overline{T 2}$ & T3 & $\overline{T 4}$ \\
\hline Pos./Neg. & $\mathrm{N}(0,1)$-statistic & .890 & .079 & -2.21 & -2.95 \\
\hline Deviation $^{\text {a) }}$ & p-value & 374 & .937 & $.027^{*}$ & $.003^{*}$ \\
\hline Average & Minimum & 73 & 93 & 227 & 228 \\
\hline Distance $^{\text {b) }}$ & Maximum & 190 & 299 & 417 & 408 \\
\hline To optimal path & Mean & 115 & 150 & 290 & 324 \\
\hline Time & $\mathrm{N}(0,1)$-statistic & 1.33 & .000 & -.863 & -1.33 \\
\hline Trend $^{c)}$ & $p$-value & .182 & 1.00 & .388 & .182 \\
\hline
\end{tabular}

Note: a) Wilcoxon-Test $\mathrm{H}_{0}: \mathrm{P}\left[\mathrm{y}_{\mathrm{t}}>\psi^{*}\right]=\mathrm{P}\left[\mathrm{y}_{\mathrm{t}}<\psi^{*}\right]$, where $\psi^{*}=0$ if $\mathrm{x}_{\mathrm{t}}<500$ and $\psi^{*}=\mathrm{x}_{\mathrm{t}}-500$ otherwise, $1<\mathrm{t}<100\left(\mathrm{x}_{\mathrm{t}}\right.$ being the stock before extraction and $\mathrm{y}_{\mathrm{t}}$ the subject's extraction); $\mathrm{H}_{1}: \mathrm{P}[.] \neq \mathrm{P}[],. \mathrm{n}=12$. $\mathrm{A}+/$ - sign indicates over-/under-harvesting. b) Within treatment average distances of subjects' stock sizes from the optimal path; minimum, maximum and mean over 100 extractions. c) Wilcoxon-Test $\mathrm{H}_{0}: \quad \mathrm{P}\left[\rho\left(\mid \mathrm{y}_{\mathrm{t}^{-}}\right.\right.$ $\left.\left.\psi^{*} \mid, \mathrm{t}\right)>0\right]=\mathrm{P}\left[\rho\left(\left|\mathrm{y}_{\mathrm{t}}-\psi^{*}\right|, \mathrm{t}\right)<0\right], 1<\mathrm{t}<100, \psi^{*}$ as above; $\mathrm{H}_{1}: \mathrm{P}[.] \neq \mathrm{P}[$.$] , where$ $\rho($.$) is the Spearman rank correlation coefficient of deviations and time,$ $\mathrm{n}=12$. The sign indicates whether the correlation is positive or negative (see Table 3 below). *Significant at $\alpha=.05$.

surprising that subjects' performance did not improve significantly. However, although average efficiency increased in T3-T4 and in T1 it decreased, the maximum average distance from the optimal path in $\mathrm{T} 1$ over all periods still is bigger than the minimum average deviations in $\mathrm{T} 3$ and T4, as indicated in the second row of Table 2. Furthermore, within a treatment we cannot find any significant majority of subjects who converged to or diverged from the optimal path: as indicated in the third row of Table 2, a two-tailed Wilcoxon signed ranks test cannot reject the null hypothesis that individual correlation coefficients of time-deviation are as likely greater as smaller than zero in any treatment. The individual Spearman correlation coefficients are reported in the right-hand section of Table 3.

The presumed objective of subjects was to maximise efficiency, i.e., without knowing the optimal path they had to minimise the distance to it in each extraction. In Table 3 the achieved individual efficiencies are recorded. Efficiency, i.e., the ratio between the actual extractions divided by the maximal possible extractions, increased from T4-T1. Subjects' mean efficiency in T1 declined from .90, T2: .72 and T3: .49 to .39 in T4. Hence, the knowledge of the growth function implied an average efficiency gain of 84 percent and the accurate information of stock size induced an increase in average efficiency of 25 percent $^{11}$. However, by comparison between treatments of subjects' attained efficiencies an enhanced performance can be verified only between T1 and T2 but not between T3 and T4. A Mann-

\footnotetext{
${ }^{11}$ Note: the stock signal varied by 25 percent around the actual stock size.
} 
Table 3. Subjects' attained efficiency and individual time trend to the optimal path

\begin{tabular}{|c|c|c|c|c|c|c|c|c|}
\hline \multirow[b]{2}{*}{ subject } & \multicolumn{4}{|c|}{ Efficiency $^{a)}$} & \multicolumn{4}{|c|}{ Spearman correlation coefficient $^{\text {b) }}$} \\
\hline & $\mathrm{T} 1$ & $\mathrm{~T} 2$ & T3 & T4 & T1 & T2 & T3 & T4 \\
\hline 1 & .706 & $.095^{\dagger}$ & .057 & .018 & $.562^{*}$ & -.444 & $-.431^{*}$ & $.395^{*}$ \\
\hline 2 & .803 & .488 & .066 & .036 & $-.324^{*}$ & .189 & -.193 & -.144 \\
\hline 3 & .810 & .507 & .168 & .056 & $-.659^{*}$ & $-.680^{*}$ & .142 & $-.288^{*}$ \\
\hline 4 & .877 & .656 & .192 & .084 & .017 & -.141 & $-.311^{*}$ & $-.338^{*}$ \\
\hline 5 & .879 & .814 & .358 & .178 & $.416^{*}$ & .191 & $-.755^{\star}$ & $-.254^{*}$ \\
\hline 6 & .917 & .836 & .484 & .267 & $.464^{*}$ & .069 & $-.333^{*}$ & -.146 \\
\hline 7 & .939 & .853 & .606 & .557 & $.497^{\star}$ & .087 & $-.806^{*}$ & $-.236^{*}$ \\
\hline 8 & .942 & .860 & .658 & .611 & $.676^{*}$ & .157 & -.163 & $.625^{*}$ \\
\hline 9 & .950 & .866 & .771 & .613 & $.704^{*}$ & .007 & $.536^{\star}$ & $-.453^{*}$ \\
\hline 10 & .974 & .890 & .791 & .686 & -.199 & .079 & $.584^{*}$ & $-.593^{*}$ \\
\hline 11 & .980 & .904 & .851 & .695 & -.099 & .107 & $.601^{*}$ & $-.383^{*}$ \\
\hline 12 & .993 & .907 & .922 & .853 & .012 & $-.224^{*}$ & $-.239^{*}$ & .052 \\
\hline Average & .898 & .723 & .494 & .388 & .167 & -.003 & -.119 & -.138 \\
\hline Std. Dev. & .087 & .247 & .317 & .309 & .429 & .248 & .478 & .339 \\
\hline
\end{tabular}

Note: ${ }^{\dagger}$ In T2, one subject extinguished the resource within 19 extractions. Her $19^{\text {th }}$ extraction was 2 units less than the signalled stock and exceeded the actual stock size. a) Subjects' results are arranged according to their performance. b) Spearman rank correlation test $\mathrm{H}_{0}: \rho\left(\left|y_{\mathrm{t}}-\psi^{*}\right|, t\right)=0$, where the optimal extraction $\psi^{*}=0$ if $\mathrm{x}_{\mathrm{t}}<500$ and $\psi^{*}=\mathrm{x}_{\mathrm{t}}-500$ otherwise ( $\mathrm{x}_{\mathrm{t}}$ being the stock before extraction and $\mathrm{y}_{\mathrm{t}}$ the subject's extraction); $H_{1}: \rho() \neq 0,.1<t<100$. Negative/positive sign indicates convergence to/divergence from the optimal path. * Significant at $\alpha=.05$-level.

Whitney two-tailed test of the null-hypothesis that extractions in the treatments T3 and T4 are equally efficient yields a p-value of $p=.378$ and can thus not be rejected at a significance level of $\alpha=.05$. It seems to suggest that a higher efficiency level is not necessarily achieved if the information about the stock size is accurate instead of noisy. With regard to the individual performance in T1, T2 and T3, respectively, the resulting p-values of the two-tailed MannWhitney test procedure are $\mathrm{p}=.045$ for the T3-T2 pair, and $\mathrm{p}=.014$ for the T1-T2 pair. These results confirm that subjects' extraction-decisions in T1 were significantly more efficient than in T2 (at $\alpha=.05$ ), and, respectively, in T2 more efficient than in T3 and in T4. Thus, high performance requires apparently a subject's knowledge of the environment. Moreover, the ability of the decision maker to make use of more accurate information seems to result in a higher efficiency only if the decision maker has a precise mental model of the decision task.

\section{The Final Extraction Decisions}

With the final extraction, subjects were expected to extinguish the resource. However, only a minority did so: 8 subjects (16.7\%) ended the experiment with a zero stock signal, 5 subjects (10\%) with a stock signal of 1 unit, and 35 out of 47 subjects (74\%) left actually more than 5 
units in the fishery. More than 83 percent of subjects hence did not intend to extract the entire resource in the final decision. ${ }^{12}$ This is remarkable, because it seems to be one of the most obvious maximisation tasks in the experiment. This can be illustrated more evidently from a different perspective, in which we consider a one-shot decision of taking any amount of money from some given pie. If this decision was a one-period (or two-period) task there should be no doubt about it that all or nearly all subjects would take everything they can. Obviously, the repeated extraction from the stock influenced subjects' behaviour such that they did not realise that the last extraction decision was different from their earlier ones. Ten percent of subjects even left one unit which indicates that they were aware of the finality of their decision, but they did not realise that they were able to extinguish the resource. ${ }^{13}$ A possible source of this confusion is induction and subject's experience. It relates to Popper (1963)'s problem of similarity: People interpret a situation as a repetition of another, although they are not identical. Subjects seem to have misjudged the situation in the last extraction on grounds of the similarity to their former tasks of not extinguishing the resource. They failed to realise the abrupt environmental change and applied their usual decision rule. ${ }^{14}$

\section{Control Theory and Misperceptions of Feedback}

According to Edwards' (1962) classical description this research is a laboratory study of dynamic decision making ${ }^{15}$. Brehmer (1992) remarked that experiments on dynamic decision making are particularly valuable since real world problems such as company management or even everyday life involve many dynamic tasks, and field data is difficult to obtain. As a general framework for the study of dynamic decision making, Brehmer (1992) suggested control theory (although not the mathematical term) ${ }^{16}$. He pointed out, subjects' overall goal in a

\footnotetext{
${ }^{12}$ The pair-wise comparisons between treatments of remaining stocks did not yield any significant differences (two-tailed Mann-Whitney test, $\alpha=.05, \mathrm{n}_{1}=\mathrm{n}_{2}=12$ (in T2 $\mathrm{n}=11$ )).

${ }^{13}$ One might suspect that subjects with a lower efficiency in the first 99 periods performed worse also in the final extraction. However, the one sample runs tests on the data (subjects ordered by performance) of each treatment accept the null-hypotheses of equal performance in the last period regardless of the performance in earlier periods ( $p>74$ taking the mean as the reference point).

${ }^{14}$ Brehmer (1980) reported of several studies in which subjects performed not better if they were experienced in specific tasks or not. Our data suggests that experience in certain circumstances might even worsen performance.

${ }^{15}$ A dynamic decision problem implies that 1) a series of decisions is required to reach the goal, 2) the decisions are not independent, and 3) the state of the decision problem changes. See Brehmer (1992) for a discussion.

${ }^{16}$ This was noted before; see for instance Rapoport (1975).
} 
dynamic decision task should be one of "... achieving control: that is, that decisions are made to achieve some desired state of affairs, or to keep a system in some desired state."

Founding on the idea that subjects are trying to take control over the dynamical system we can establish the research hypothesis that subjects try to hold either the stock signal or the extraction level constant (through the extractions 2-99) ${ }^{17}$.

Table 4. Time trend of individual extractions and size of stock signals

\begin{tabular}{|c|c|c|c|c|c|c|c|}
\hline & & & T1 & T2 & T3 & T4 & Total \\
\hline Time & $\# P(\rho)$ & $(t)=0)<.05^{c)}$ & 5 & 2 & 8 & 7 & 22 \\
\hline Trend & & [\%] & [41.7\%] & [16.7\%] & [66.7\%] & [58.3\%] & [45.8\%] \\
\hline \multirow{2}{*}{$\begin{array}{l}\text { Extrac- } \\
\text { tions }^{a)}\end{array}$} & \multirow[t]{2}{*}{$\overline{W T^{d)}}$} & $\mathrm{N}(0,1)$-statistic & -.706 & -.078 & .706 & 1.334 & .954 \\
\hline & & $\mathrm{p}$-value & .480 & .937 & .480 & .182 & .340 \\
\hline Time & \multicolumn{2}{|c|}{$\# P\left(\rho\left(z_{t}, t\right)=0\right)<.05^{e)}$} & 8 & 7 & 9 & 7 & 31 \\
\hline Trend & & {$[\%]$} & [66.7\%] & {$[50 \%]$} & {$[75 \%]$} & [66.7\%] & [64.6\%] \\
\hline Stock & & $\mathrm{N}(0,1)$-statistic & -2.275 & -1.334 & -2.589 & -1.883 & -4.087 \\
\hline Signal $^{\text {b) }}$ & & $p$-value & $.023^{*}$ & .182 & $.010^{*}$ & .060 & $.000^{*}$ \\
\hline Stock vs. & \multirow[t]{2}{*}{$\mathrm{WT}^{\mathrm{g})}$} & $\mathrm{N}(0,1)$-statistic ${ }^{\text {h) }}$ & 2.746 & 2.040 & 1.490 & 0.549 & 3.569 \\
\hline Extraction & & $p$-value & $.006^{*}$ & $.041^{*}$ & .136 & .583 & $.000^{*}$ \\
\hline
\end{tabular}

Note: Tests are conducted on individual correlation coefficients with respect to a) a subject's extractions $1<t<100$, b) the size of a subject's stock signal after extraction $1<\mathrm{t}<100$. c) Number of subjects whose extractions increase or decrease significantly over time [in percentage, $\mathrm{n}=12, \mathrm{~N}=48$ ] (two-tailed Spearman rank correlation test, $\alpha=.05$, $\left.1<\mathrm{t}<100, \mathrm{H}_{0}: \rho\left(\mathrm{y}_{\mathrm{t}}, \mathrm{t}\right)=0, \mathrm{H}_{1}: \rho() \neq 0.\right)$. d) two-tailed Wilcoxon signed ranks test of Spearman correlation coefficient $\mathrm{H}_{0}: \mathrm{P}\left(\rho\left(\mathrm{y}_{\mathrm{t}}, \mathrm{t}\right)>0\right)=\mathrm{P}\left(\rho\left(\mathrm{y}_{\mathrm{t}}, \mathrm{t}\right)<0\right), \mathrm{H}_{1}$ : not $\mathrm{H}_{0}, \mathrm{n}=12$, $\mathrm{N}=48$. e) Number of subjects whose stock signal after extraction increased or decreased significantly over time [in percentage, $\mathrm{n}=12, \mathrm{~N}=48$ ] (two-tailed Spearman rank correlation test, $\alpha=.05,1<\mathrm{t}<100$, $\left.\mathrm{H}_{0}: \rho\left(\mathrm{z}_{\mathrm{t}}, \mathrm{t}\right)=0, \mathrm{H}_{1}: \rho() \neq 0.\right)$. f) Results of two-tailed Wilcoxon signed ranks test of Spearman correlation coefficient $\mathrm{H}_{0}: \mathrm{P}\left(\rho\left(\mathrm{z}_{\mathrm{t}}, \mathrm{t}\right)>0\right)=\mathrm{P}\left(\rho\left(\mathrm{z}_{\mathrm{t}}, \mathrm{t}\right)<0\right), \mathrm{H}_{1}$ : not $\mathrm{H}_{0}, \mathrm{n}=12, \mathrm{~N}=48$. g) Twotailed Wilcoxon signed ranks test of Spearman rank correlation coefficient $\mathrm{H}_{0}$ : $\left|\rho\left(y_{t}, t\right)\right|=\left|\rho\left(z_{t}, t\right)\right|, H_{1}$ : not $H_{0}$. h) Sign indicates greater correlation between stock and time than between extraction and time. *Significant at $\alpha=.05$.

The size of the stock signal after extraction decreased from extraction 2 to 99 in all treatments as was suggested already by Figure 2. This decreasing trend was significant on the individual level in treatment $\mathrm{T} 1$ and $\mathrm{T} 3$ as confirmed by the result of a two-tailed Wilcoxon signed ranks test reported in the second row of Table 4: Subjects reduce their stocks over time and do not hold them constant. In T2 and T4 a trend towards a smaller stock existed also, but less importantly. A possible explanation could be that subjects were more cautious about not extinguishing the resource when their stock signal was not accurate. In total we observe 31 subjects (64.6 percent) who significantly decreased or increased in time their after extraction

\footnotetext{
${ }^{17}$ In fact, it is difficult to distinguish between both goals (especially in T1 and T3) since we consider a deterministic microworld in which variables are interdependent.
} 
stock signal. Conducting the same analysis with regard to the extraction dynamics results in less severe outcomes, as reported in the first row of Table 4. Although 22 subjects (45.8 percent) increased or decreased their extractions over the finite horizon of the experiment, there were no significant trends on the aggregate. In the last row of Table 4 the results of a two-tailed Wilcoxon signed ranks test are recorded which compares the size of time correlation coefficient of the subject's extraction decisions with the time correlation coefficient of the subject's stock signals after extraction. The results indicate a greater correlation between time and the stock signal. Thus it seems as if subjects did not make use of their feedforward information in T1-T2 in order to control the future stock but rather intended to hold the extraction levels constant. Evidence is thus a bit ambiguous.

In Figures I-IV of the appendix the trajectories of the individual after-extraction stock sizes and signals are depicted. They are arranged from the upper left to the lower right displaying subjects' results from the least efficient to the most efficient decision maker. The figures reveal that in the experiment we observed a wide range of behaviour. However, some patterns seem striking.

For instance, most of the six least efficient subjects in T3 and T4 hold the stock very close to the biological equilibrium size of 1000 units where the growth they perceived was very small and they hardly extracted anything. Let us reason about this pattern in the light of Brehmer (1980)'s observation that people tend to believe in a linear model rather than in other models. Thus, if subjects believed in a linear relationship between stock size and growth it seems not so surprising that some may assume growth to be smaller the smaller the stock is. It seems even reasonable that they could have been convinced to maximise profits by maintaining a high stock level. Such misperception in dynamical decision laboratory systems has been reported from former research: Brehmer (1992), Diehl and Sterman (1995), Paich and Sterman (1993) and Sterman (1989a, b, c) provided evidence for similar shortcomings of human behaviour in dynamic laboratory settings. Sterman (1994) wrote that “... human performances in dynamic (complex) systems is poor ... even compared to simple decision rules. ... The observed dysfunction in dynamically complex settings arises from misperceptions of feedback ${ }^{18}$. People are insensitive to non-linearities and violate basic rules of probability. The robustness of the misperception of feedback and the poor performance that lead us to create across many

\footnotetext{
${ }^{18}$ Moxnes (1998a) referred to misperceptions of bioeconomics when he reported from a fishery management experiment.
} 
domains result from two basic and related deficiencies in our mental models of complexity. First, our cognitive maps of the causal structure of systems are vastly simplified compared to the complexity of the systems themselves. Second, we are unable to infer correctly the dynamics of all but the simplest causal maps."

Another pattern due to subjects' misperceptions of feedback must be seen in the oscillations that occur in all settings although subjects were informed that the system was deterministic. These oscillations are persistent throughout the experiment. Particularly surprising seems that subjects even in the simple setting of T1 (in which they had feedforward information) induce cycles and oscillations in the standing stock, as depicted in Figure I, instead of just holding it constant. Sterman (1989a, b, 1994) argued that in dynamically complex experimental economic systems such oscillations would arise from subjects' misperceptions of feedback. The persistency of these oscillations may be explained by the Paich and Sterman (1993)'s observation of subjects' poor learning in complex environments, and from the fact that subjects did not receive signals in the payoff-space such that they could not learn much from the feedback about the optimal strategy.

Finally, a pattern of decision behaviour relates to a rather small group of subjects who seem to have applied some kind of experimentation: in the early extractions they deplete the resource nearly to extinction (thus that they had the stock once to its both extremes) and then continue harvesting at a middle range. Puzzling, however, is that this behaviour cannot be observed in treatment $\mathrm{T} 4$ where it would be rather reasonable than in treatments $\mathrm{T} 1-\mathrm{T} 2 \mathrm{in}$ which subjects received feedforward information and therefore could not learn anything new from such experience.

\section{Summary}

In this research the fishery management problem was implemented under a finite-horizon condition. We established the benchmark solution which disagrees with the infinite-horizon solution only in the last extraction. This approach differed from other fishery experiments as in Moxnes (1998a) or Mason and Phillips (1997) in whose studies "infinite" horizon tasks were intended but sessions lasted only 20 or 35 extraction periods ${ }^{19}$. As in their studies, extinction of

\footnotetext{
${ }^{19}$ Mason and Phillips (1996) considered a dynamic extraction game in which they varied the number of extractors from the common pool. Moxnes (1998) reported an experiment in which subjects acted as soleowners of the fishery. The optimal solution to the management problem could only be determined numerically. The task was as of infinite horizon: Subjects had to maximise over the horizon of 20 periods the sum of extractions and remaining fish units. The control variables were the orders of vessels and utilization level of the
} 
the resource before the end of the experiment was not a problem, although it eventually happened. Over-harvesting was not a problem either in our study. This result diverges from those of Moxnes (1998a, b) and may feed back to the differences in the experimental structure: here, subjects had a direct control over the resource-pool while settings in Moxnes' studies were much more complex. However, we observe, as Moxnes does, pattern which can be explained by subjects' misperceptions of feedback: when subjects were not informed about the growth function some seemed to assume a linear one. It would explain to some extent why some subjects maintained the stock size at the biological equilibrium. Furthermore we observe oscillations in all settings. Sterman et al. pointed out that in dynamic decision problems these oscillations are due to the misperceptions of feedback.

Although misperceptions of feedback were a determining factor in subjects' behaviour, we observed high efficiency gains as a consequence of a richer information structure. Efficiency of extraction-decisions was on average $25 \%$ higher if the stock signal was accurate, and $84 \%$ higher if the growth-function was revealed to the subjects. Subjects' harvesting policy was significantly more efficient given an accurate stock signal only if the growth function was known; and the spread of efficiencies between subjects in a treatment was smaller with knowledge of the resource's growth. It suggests that population surveys which stress the reproduction activity of the species increase the efficiency of extraction-decisions considerably. However, it should be noted that we considered here a highly simplified, deterministic model in which the precise growth function is given or not. In a real world resource management problem the decision maker faces an inaccurate growth model and stochastic fluctuations of stocks.

Another striking result of our study was subjects' misjudgement of similarity which implied that they wasted the resource in the last extraction. This observation questions the practices of some laboratory studies in which final stocks are evaluated at fixed rates.

In following research we intend to conduct studies with an increase of complexity by introduction of positive interest rates, costs, and endogenous prices. The logistic growth function which we considered in the experiment seems to be ideally behaved to provide the experimenter with a rich research environment: the unique optimal solution to the 
maximisation problem can be calculated, although it is not easily recognised by experimental subjects. 


\section{References}

Abbink, K. and A. Sadrieh, 1995, "Ratimage, research assistance toolbox for computer-aided human behavior experiments," Discussion paper B-325, University of Bonn.

Bellman, R., 1957, Dynamic Programming, Princeton University Press, Princeton.

Brehmer, B., 1989, “In One Word: Not From Experience,” Acta Psychologica 45: 223-41.

Brehmer, B., 1992, “Dynamic Decision Making: Human Control of Complex Systems," Acta Psychologica 81: 211-41.

Clark, C. W., 1976, Mathematical Bioeconomics, John Wiley \& Sons, New York.

Diehl, E., and J. D. Sterman, 1995, "Effects of Feedback Complexity on Dynamic Decision Making," Organizational Behavior and Human Decision Processes 62 (2): 198-215.

Gordon, S. H., 1954, "The Economic Theory of a Common Property Resource: The Fishery," Journal of Political Economy 62: 124-142.

Mason, C. F. and O. R. Phillips, 1997, "Mitigating the tragedy of the commons through cooperation: an experimental evaluation," Journal of Environmental Economics and Management 32: 148-172.

Moxnes, E., 1998a, "Not Only the Tragedy of the Commons: Misperceptions of Bioeconomics," Management Science 44: 1234-1248.

Moxnes, E., 1998b, "Overexploitation of Renewable Resources: The Role of Misperceptions," Journal of Economic Behavior and Organization 37: 107-127.

Paich, M. and J. D. Sterman, 1993, "Boom, bust, and failure to learn in experimental markets," Management Science 39 (12): 1439-1458.

Popper, K. R., 1963, Conjectures and Refutations. Routledge \& Kegan, London.

Rapoport, A., 1975, "Research Paradigms for the Study of Dynamic Decision Behavior," in Wendt, D. and C. Vlek (eds.), Utility, Probability and Human Decision Making: 349369, Reidel, Dordrecht.

Sterman, J. D., 1989a, "Deterministic Chaos in an experimental economic system," Journal of Economic Behavior and Organization 12: 1-28.

Sterman, J. D., 1989b, "Misperception of feedback in dynamic decision making," Organizational Behavior and Human Decision Processes 43 (3): 301-335.

Sterman, J. D., 1989c, "Modelling Managerial Behavior: Misperceptions of Feedback in a Dynamic Decision Making Experiment," Management Science 35 (3): 321-339.

Sterman, J. D., 1994, "Learning In and About Complex Systems," System Dynamics Review $10(2-3): 291-330$. 


\section{Appendix}

Figure I. Stock size/signal after individual extractions in $\mathrm{T}^{\text {a) }}{ }^{\text {}}$
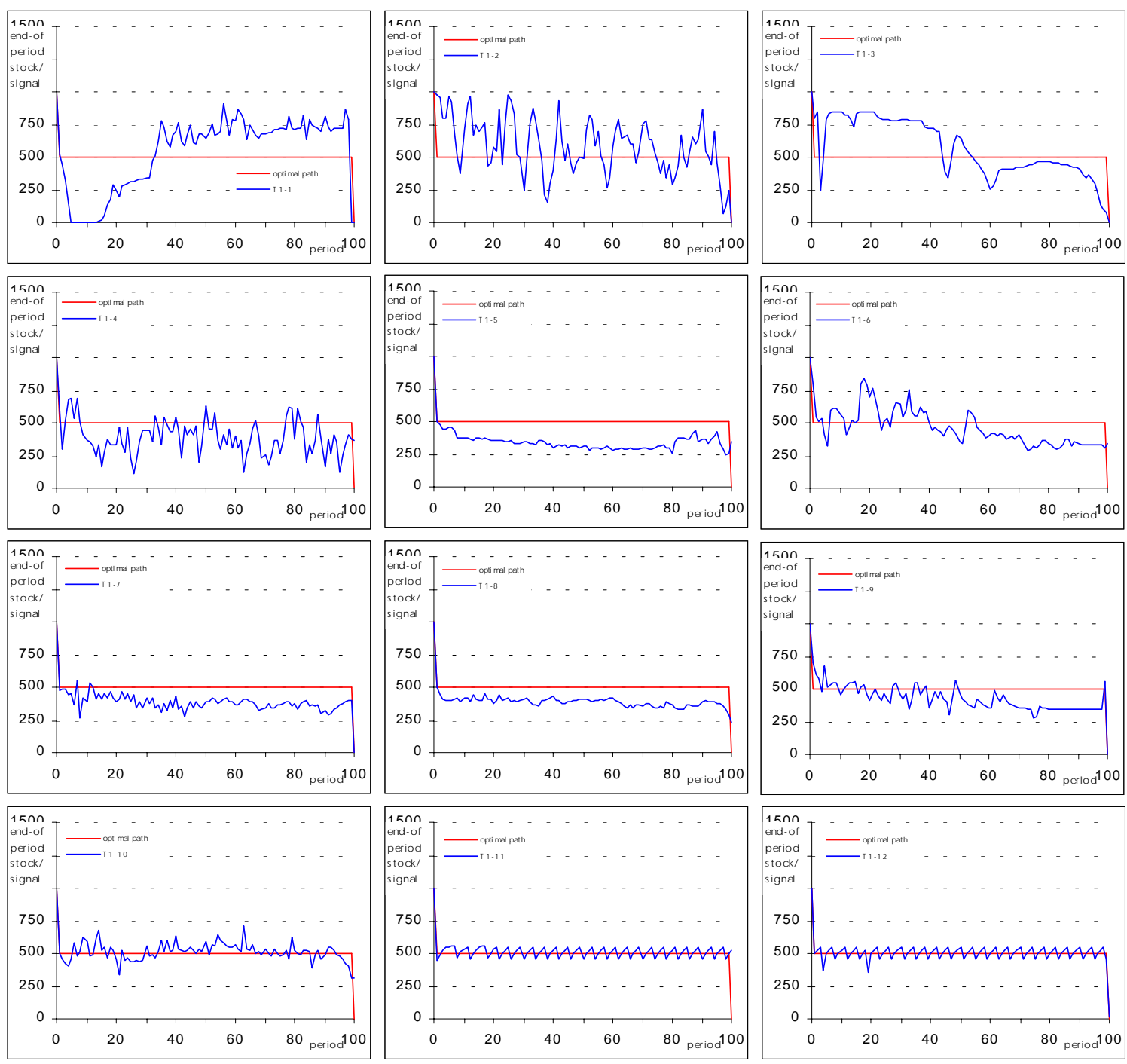

Note: a) trajectories are ordered according to the efficiency of the subject from most efficient to least efficient. 
Figure II. Stock size/signal after individual extractions in T2 ${ }^{\text {a) }}$
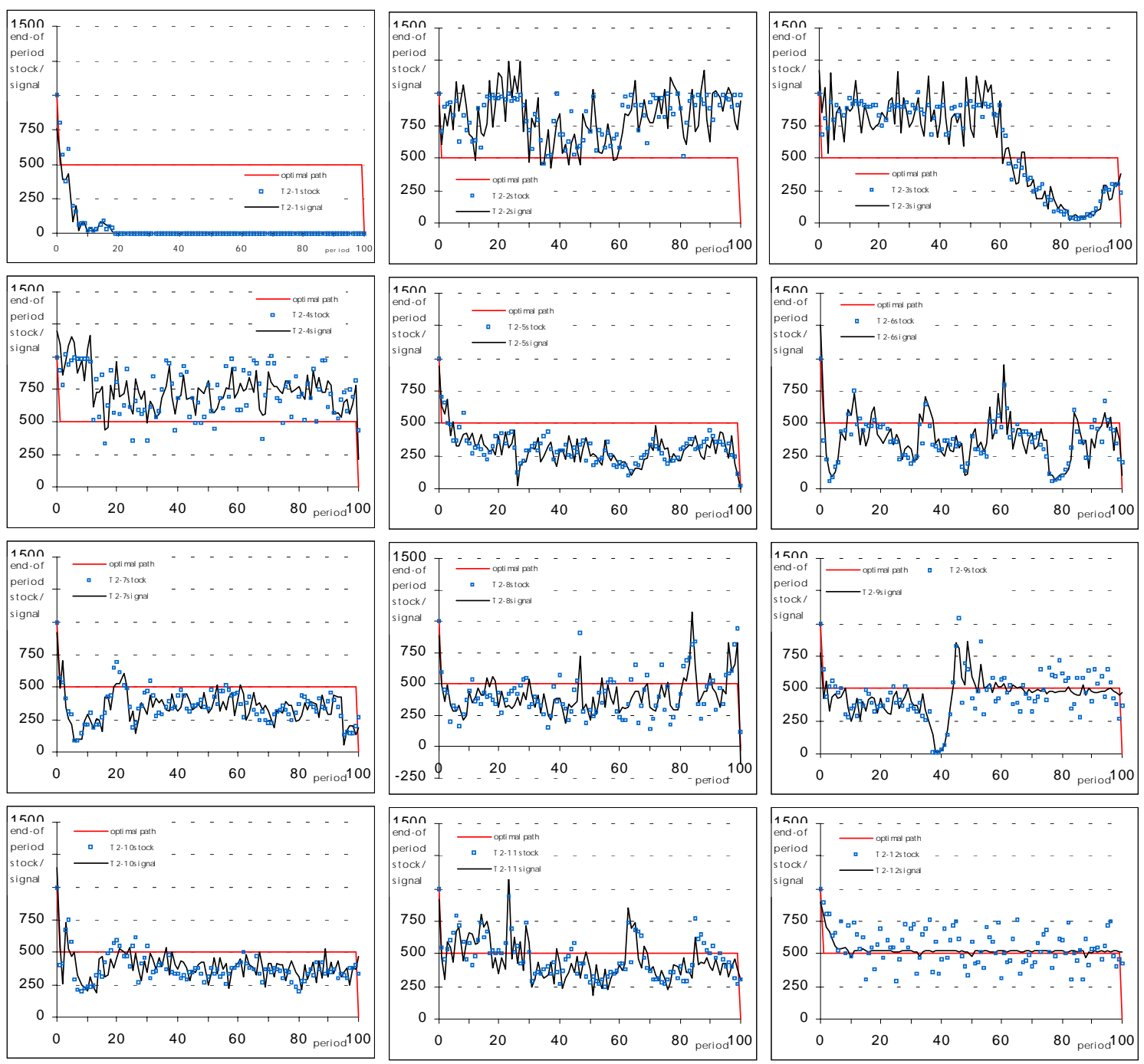

Note: a) trajectories are ordered according to the efficiency of the subject from most efficient to least efficient. The dots refer to the actual stock size, the curve to the stock signal and the straight line to the optimal path. 
Figure III. Stock size/signal after individual extractions in T3 ${ }^{\text {a) }}$
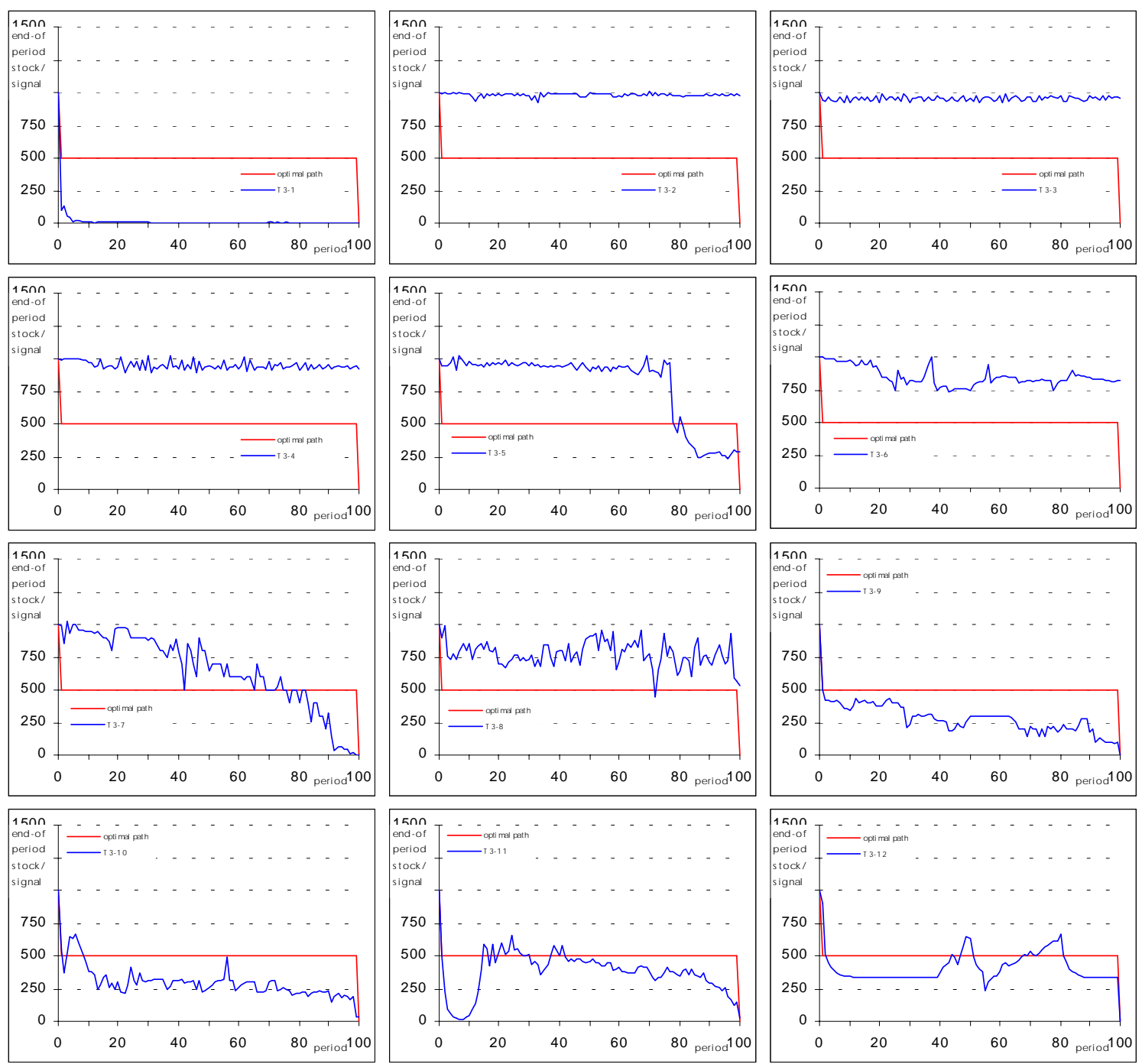

Note: a) trajectories are ordered according to the efficiency of the subject from most efficient to least efficient. 
Figure IV. Stock size/signal after individual extractions in $\mathrm{T} 4^{\text {a) }}$
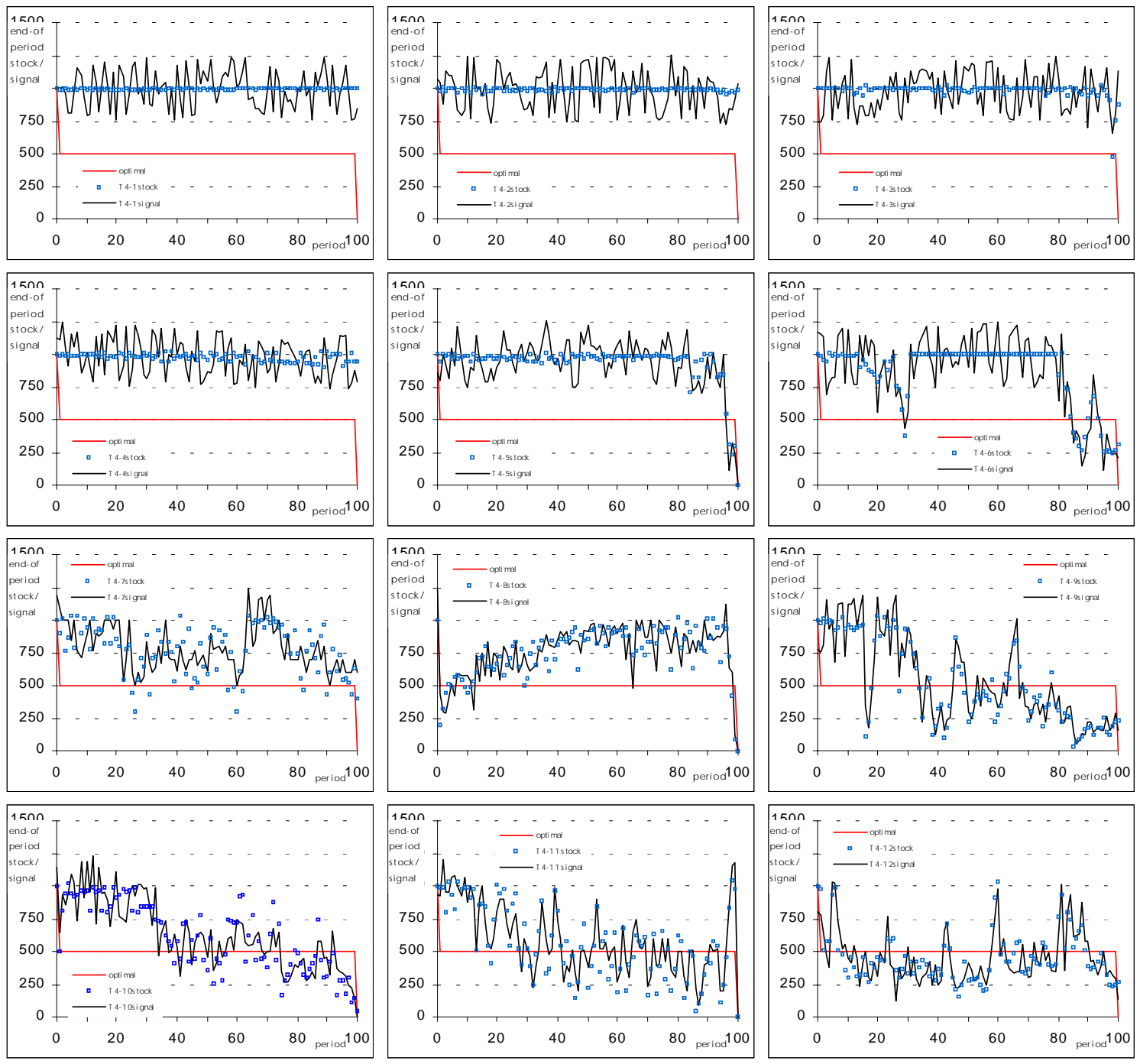

Note: a) trajectories are ordered according to the efficiency of the subject from most efficient to least efficient. The dots refer to the actual stock size, the curve to the stock signal and the straight line to the optimal path. 


\section{Instructions}

In the experiment you will have to take 100 saving decisions: you must decide how many units you want to extract from a stock of some fictitious resource. Every extracted unit will be added to your savings. Your task in the experiment is to maximise your savings during the 100 extractions. After each extraction the stock will grow deterministically, i.e., the growth is not random but depends on the number of units remaining after extraction from the stock.

Before you extract units from the stock you will be informed about the existing stock size. [subjects in T2 and T4 read: However, your information will not be accurate but will be subject to a random draw which varies from $75 \%$ and $125 \%$ around the true stock.]

Note: if your stock falls to zero at any time, your extraction in the remaining periods will be zero by defect.

[subjects in $\mathrm{T} 1$ and $\mathrm{T} 2$ read: The growth function

By means of an on-screen facility (under the title "result calculation") you will be able to calculate the growth, the corresponding stock after (and before the next) extraction which result from any hypothetical extraction. As a standard, this information will provided for any 10 percentile (i.e., $10 \%, 20 \%, \ldots, 100 \%$ ) of your stock.]

\section{Your payoff}

There exists an optimal extraction plan about which you will not receive any information. However, at the end of the experiment your payoff will be determined relatively to the maximal possible savings: let $\mathrm{X}$ be your savings after 100 extractions and $\mathrm{Y}$ the maximal achievable savings, your payoff will be equal to $\mathrm{X} / \mathrm{Y}^{*}\{$ (subjects in T1 read 25000), (subjects in T2 and T3 read 30000), (subjects in T4 read 35000)\} Lire.

\section{The original instructions in Italian:}

NB: L'obiettivo di quest'esperimento e' studiare come gli individui prendono decisioni economiche. I dati collezionati in questo studio devono essere indipendenti l'uno dall'altro. Per questo motivo e' importantissimo che tutti i partecipanti in quest'esperimento prendano le proprie decisioni da soli. Se hai dubbi circa l'esperimento alza la mano prima di fare la tua domanda. Non potete assolutamente comunicare tra di voi, pena l'esclusione dall'esperimento.

Nell'esperimento devi prendere 100 decisioni di risparmio. Devi sempere decidere quante unita` vuoi estrarre da una scorta di una certa risorsa. Ogni unita`estratta si aggiungera` al tuo risparmio. Il tuo obiettivo nell'esperimento e' massimizare il tuo risparmio durante le 100 estrazioni. Dopo ogni estrazione la scorta crescera` deterministicamente (questo vuole dire che la crescita della scorta non dipende dal caso, ma solamente dalle unita`che rimangono nella scorta dopo l'estrazione).

Prima di ogni estrazione sarai informato/a sulla scorta disponibile. [T2 e T4: Cio` nonostante la tua informazione non sara` essata ma variera` casualmente nell'intorno di $75 \%$ e di $125 \%$ della vera scorta.]

NB: se durante l'esperimento la tua scorta diventa 0 tutte le successive estrazioni saranno uguali a 0 automaticamente.

[T1 e T2: La funzione di crescita

Mediante un dispositivo sul tuo schermo (sotto la voce "calcolo dei risultati") potrai calcolare la crescita e la scorta prossima derivante da qualsiasi ipotetica estrazione. Come standard questa informazione e' presentata sul tuo schermo per tutti i 10 percentili $(10 \%, 20 \%, \ldots, 100 \%)$ della tua scorta.]

Il tuo profitto

C'e` un programma di estrazione ottimo del quale non riceverai nessuna informazione. Cio` nonostante, alla fine dell'esperimento il tuo profitto sara' determinato relativamente al risparmio massimo: sia $\mathrm{X}$ il tuo risparmio dopo 100 estrazioni e Y il risparmio massimo, il tuo profitto sara uguale a X/Y*\{25000, 30000, 30000, 35000 \} Lire. Questo importo ti sara` pagato alla fine dell'esperimento in contanti. 


\section{The screen}

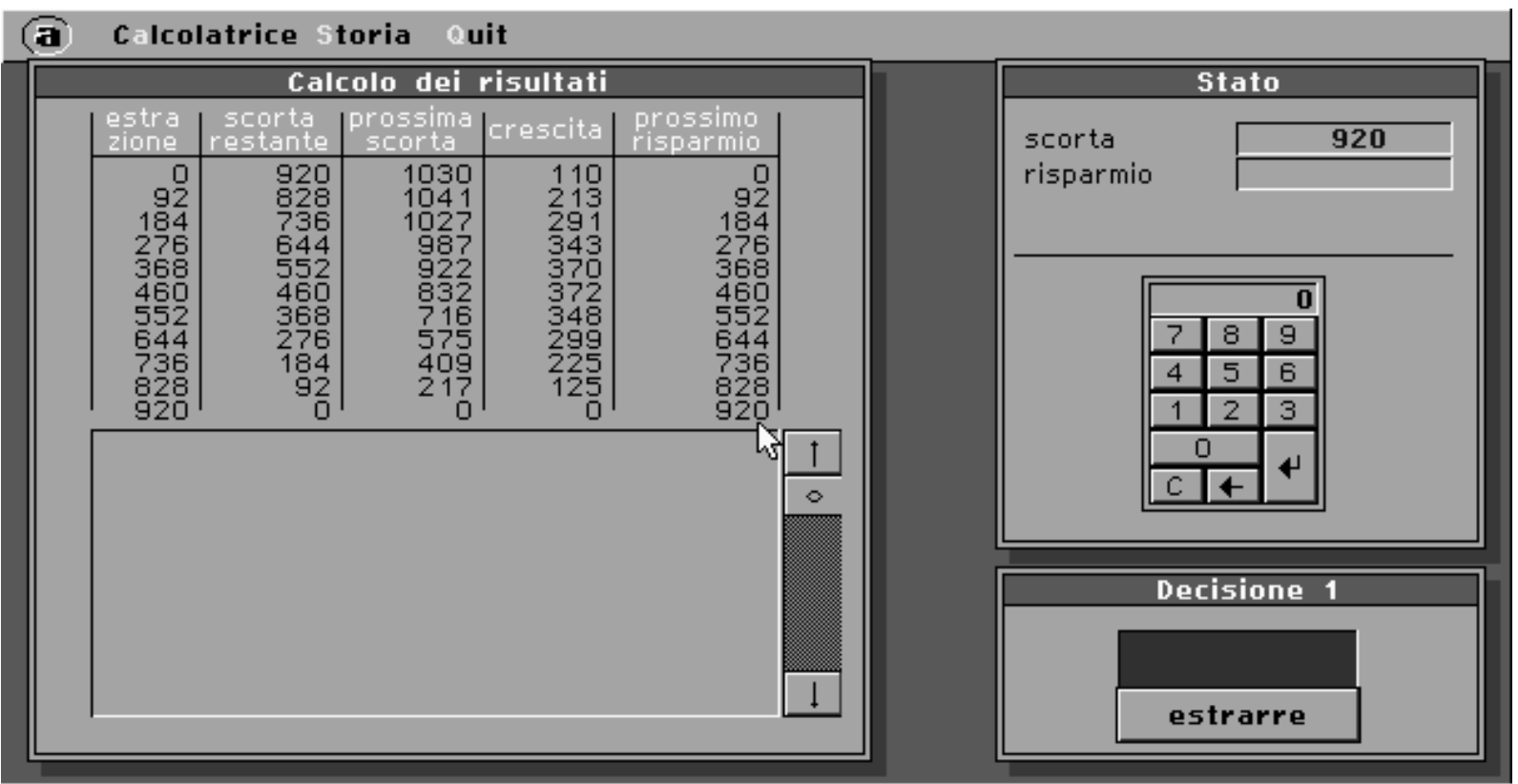

(E) Usa il tastierino numerico per scegliere la tua extrazione. 